\title{
Lusioersily
}

\section{Using Artificial Neural Networks to predict short-term wholesale prices on the Irish Single Electricity Market}

Li, P., Arci, F., Reilly, J., Curran, K., Belatreche, A., \& Reilly, J. (2016). Using Artificial Neural Networks to predict short-term wholesale prices on the Irish Single Electricity Market. In Unknown Host Publication IEEE. https://doi.org/10.1109/ISSC.2016.7528467

Link to publication record in Ulster University Research Portal

\section{Published in:}

Unknown Host Publication

Publication Status:

Published online: 04/08/2016

DOI:

10.1109/ISSC.2016.7528467

\section{Document Version}

Publisher's PDF, also known as Version of record

\section{General rights}

Copyright for the publications made accessible via Ulster University's Research Portal is retained by the author(s) and / or other copyright owners and it is a condition of accessing these publications that users recognise and abide by the legal requirements associated with these rights.

\section{Take down policy}

The Research Portal is Ulster University's institutional repository that provides access to Ulster's research outputs. Every effort has been made to ensure that content in the Research Portal does not infringe any person's rights, or applicable UK laws. If you discover content in the Research Portal that you believe breaches copyright or violates any law, please contact pure-support@ulster.ac.uk. 


\title{
Using Artificial Neural Networks to predict short-term wholesale prices on the Irish Single Electricity Market
}

\author{
Pengfei Li, Francesco Arci, Jane Reilly \\ Ark Energy Consulting Limited \\ Unit 20 Daingean Hall, N4 Axis Centre, \\ Battery Road, Longford. \\ \{pengfei.li, francesco.arci, jane.reilly\} @ ark-energy.eu
}

\author{
Kevin Curran, Ammar Belatreche \\ Faculty of Computing and Engineering \\ Ulster University \\ Northern Ireland \\ \{kj.curran, a.belatreche\}@ulster.ac.uk
}

\begin{abstract}
Electricity markets are different from other markets as electricity generation cannot be easily stored in large amounts and in order to avoid blackouts, the generation of electricity must be balanced with customer demand for it on a second-by-second basis. Customers tend to rely on electricity for day-to-day living and cannot replace it easily so when electricity prices increase, customer demand generally does not reduce significantly in the short-term. As electricity generation and customer demand must be matched perfectly second-by-second, and because generation cannot be stored to a large extent, cost bids from generators must be balanced with demand estimates in advance of real-time. This paper outlines a a forecasting algorithm built on artificial neural networks in order to predict shortterm (72 hours ahead) wholesale prices on the Irish Single Electricity Market so that market participants can make more informed trading decisions. Research studies have demonstrated that an adaptive or self-adaptive approach to forecasting would appear more suited to the task of predicting energy demands in territory such as Ireland. Implementing an in-house self-adaptive model should yield good results in the dynamic uncertain Irish energy market. We have identified the features that such a model demands and outline it here.
\end{abstract}

\section{Introduction}

The increasing percentage of electricity generated through renewable sources tends to invalidate the assumption of correlation between electricity spot prices and the price of the mix of commodities utilized to supply generators (e.g. gas, coal, oil - depending on the generating asset composition on the specific grid). The variable nature of production of renewable energy sources also increases the volatility of system marginal prices (SMPs) on markets based on a mandatory central pool model. European countries have undertaken substantial investments to boost the amount of energy produced through renewable generation. Ireland in particular is aiming at $40 \%$ of its power needs being met by renewable sources by 2020. In this environment, we can expect the wholesale, fine granularity (e.g. half hourly) wholesale price of electricity to become more volatile over time. The ability to operate effectively on electricity spot markets relies on the capability to devise appropriate bidding strategies. These in turn can benefit from the inclusion of a reliable forecast of short term system marginal prices (SMPs). In a market with an increasing percentage of renewable generators, reliable forecasts must necessarily take into account additional factors such as meteorological forecasts, forecasted demand and constraints imposed by network topology. Traditional time series forecasting algorithms (e.g. based on AutoRegressive Integrated Moving Average models) can perform reasonably well in this context but rely on assumptions being made on behavior over different temporal windows to yield consistent results (Werbos, 1975).

This paper is organised as follows: Section 2 provides a background to the Single Electricity market in Ireland, section, section 3 provide an overview of related work in short term forecasting in electricity market, section 4 introduces Artificial Neural Networks \& Short-term Load Forecasting, section 5 presents the short-term forecasting model and section 6 provides a conclusion.

\section{Single Electricity Market}

The Single Electricity Market (SEM) is the wholesale electricity market for the island of Ireland, regulated jointly by the CER and its counterpart in Belfast, the Utility Regulator. The Commission for Energy Regulation (CER) is the 
independent body responsible for regulating the natural gas and electricity markets in Ireland. By combining what were two separate jurisdictional electricity markets, the SEM became one of the first of its kind in Europe when it went live on 1st November 2007 (CER, 2011). The SEM is designed to provide for the least cost source of electricity generation to meet customer demand at any one time across the island, while also maximising long-term sustainability and reliability. The SEM is operated by SEMO, the Single Electricity Market Operator, a joint-venture between EirGrid and SONI, the transmission system operators in Ireland and Northern Ireland respectively. SEMO ${ }^{1}$ is responsible for administering the market, including paying generators for their electricity generated and invoicing suppliers for the electricity they have bought (CER, 2011). SEM consists of a centralised and mandatory all-island wholesale pool (or spot) market, through which generators and suppliers trade electricity. Generators bid into this pool their own short-run costs for each half hour of the following day, which is mostly their fuel-related operating costs. Based on this set of generator costs and customer demand for electricity, the System Marginal Price (SMP) for each half-hour trading period is determined by SEMO, using a stack of the cheapest all-island generator cost bids necessary to meet all-island demand. It is these more efficient generators which are generally run to meet demand in the half hour in what is known as the "Market Schedule". More expensive or inefficient generators are "out of merit" and hence they are not run and are not paid SMP, keeping customers' bills down as shown in Figure 1.

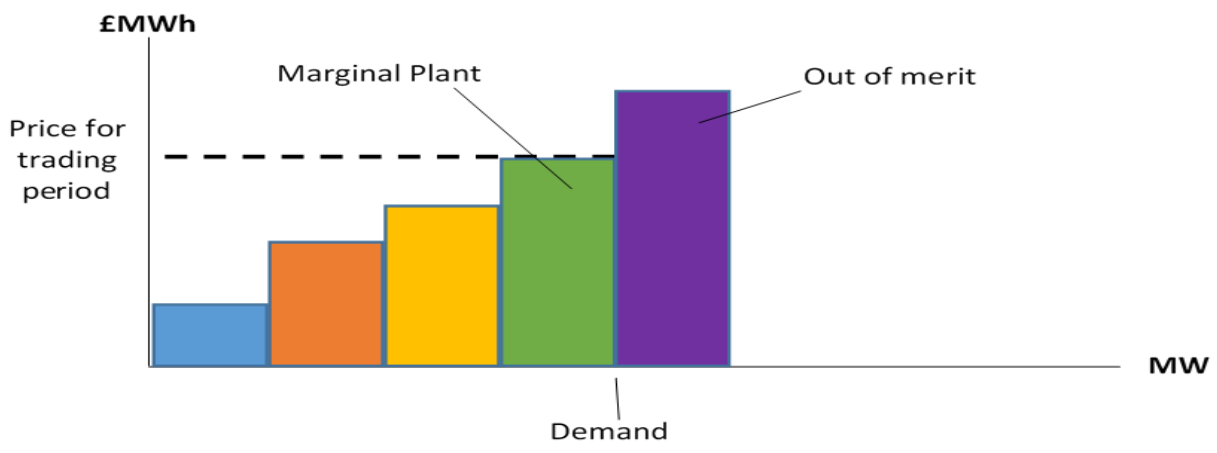

Figure 1: The role of System Marginal Price

The SMP for each half hour is paid to all generators that are needed to meet demand. Suppliers, who sell electricity direct to the final consumer, buy their electricity from the pool at this common price, as illustrated in Figure 2. Overall the SEM facilitates the running of the cheapest possible generators, determined by the stack of generation cost bids, to meet customer demand across the island. This mandatory centralised pool model in SEM, in which all key generators and suppliers must participate, differs from most other European markets in which most trade takes place bilaterally between generators and suppliers. In these bilateral markets only a residual amount of electricity is traded in an exchange, primarily for balancing purposes. In contrast all key players must trade in SEM, so there is more transparency associated with SEM prices and market outcomes.

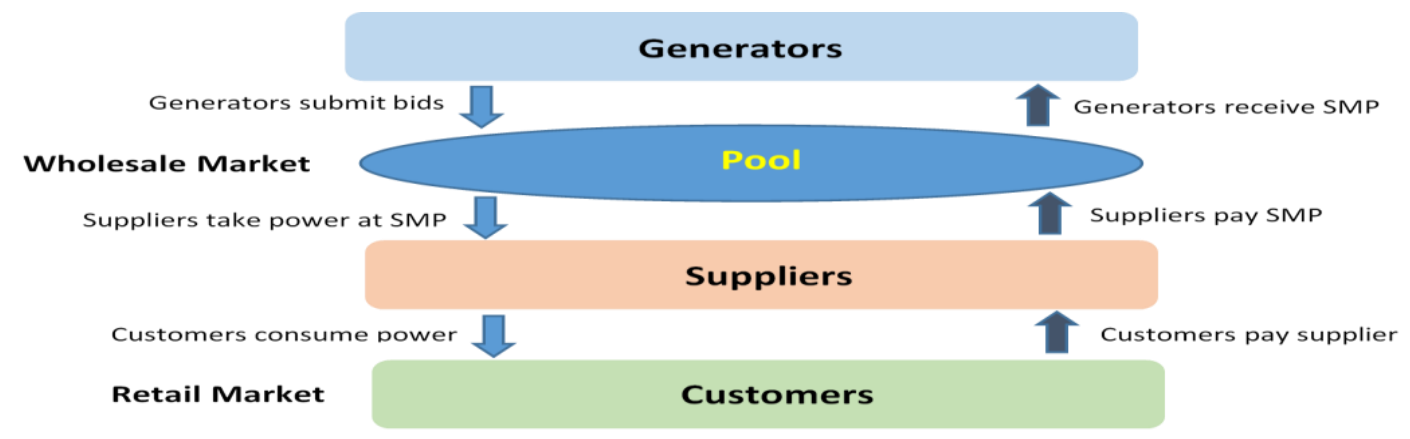

Figure 2: Wholesale and retail market

\footnotetext{
${ }^{1}$ www.sem-o.com.
} 
Generators operating within the SEM also receive separate capacity payments which contribute towards their fixed costs, if they are available to generate. The capacity payment pot of money for generators is set ahead of time by the SEM Committee and is calculated based on the relatively low fixed costs of a peaking plant. As a result the payments generally cover only a portion of the fixed costs involved in building most plants. Suppliers also pay for these capacity payments and any other system charges, which are typically passed through to customers. In order to sell electricity into the SEM pool, generators must submit cost bids to SEMO the day before the physical trade/generation takes place, known as D-1. The bids submitted are primarily based on a generator's running or Short Run Marginal Cost (SRMC), i.e. the cost of each extra MW it could produce excluding its fixed costs. The SRMC reflects the opportunity cost of the electricity produced, which is the economic activity that the generator forgoes to produce electricity. For example, in the case of a generator fuelled by gas, the opportunity cost includes the price of gas on the day that it is bidding in, because if the generator was not producing electricity it could sell its gas in the open market. Generator bids also include a generator's start-up costs, which are costs it faces if it needs to be turned on after a period of inactivity, as well as generator no-load costs which are (mostly fuel) costs which are indifferent to output levels. The generators submit these bids to SEMO up until Gate Closure, currently at 10:00am on D-1. Software is then run by SEMO to determine a Market Schedule which forecasts the SMP for each half hour trading period for the following day. However no software can predict with complete accuracy what will happen in reality: real-time factors such as a change in wind generation or customer demand, which can affect SMP, must be accounted for. For this reason, SEMO completes two more software runs reflecting the reality of what actually happened in generator dispatch, one on the day after the trading day (D+1), and another four days after (D+4), to calculate the final SMP for each half hour of the trading day. This D+4 price is the one that is paid to generators and paid by suppliers. The Market Schedule identifies the lowest cost solution at which generation can meet demand for each half hour trading period. It ranks generators with the lowest bids first until the quantity needed for the demand is met - see blue shaded bars in Figure 3. The marginal generator needed to meet the demand sets the SMP for that trading period. The other generators who have submitted SRMC bids lower than this price are deemed to be "in merit" and will also be scheduled to run. All generators who have submitted bids which are higher than this price (SMP) are deemed to be "out of merit", and will not be scheduled to run - see the green bar in Figure 3. These tend to be old or inefficient plants.

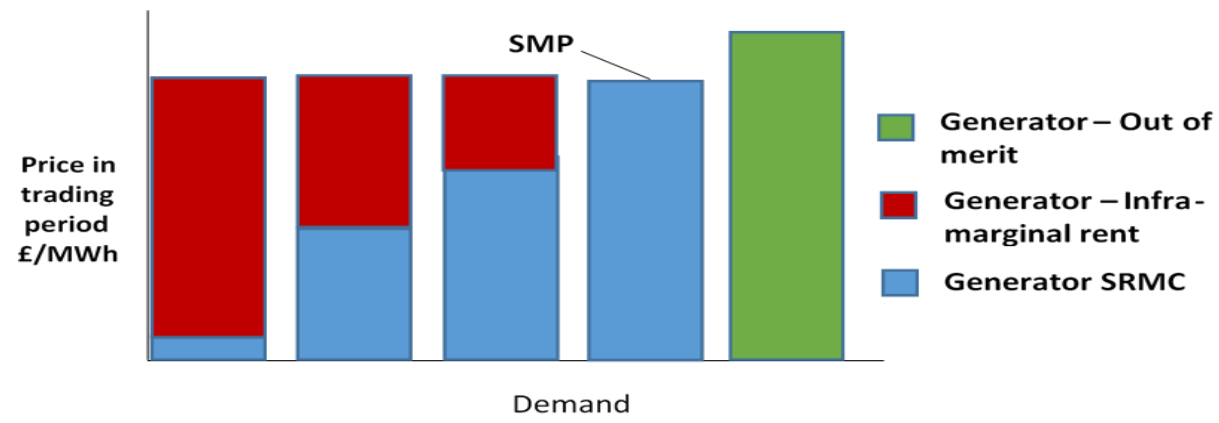

Figure 3: Market schedule

All generators who have submitted a bid which is under the SMP earn a profit, known as "inframarginal rent", on the difference between their SRMC bid offer and the SMP. This is illustrated in red shaded bars in the graph. The plant that sets the marginal price in a half hour, i.e. the one with the highest running costs among those that are scheduled to run, does not receive any infra-marginal rent. However this is typically a peaking plant which, while it has high short-run costs, has low fixed costs. Hence its costs are covered through the SMP and the capacity payments it receives. Infra-marginal rent is needed for most generators that are run, including efficient modern gas plants and wind farms, because while such plants have relatively low running costs (SRMC), they have much higher fixed costs which the (relatively low) capacity payment does not fully cover. Without infra-marginal rent, it would not be economic to build modern efficient power plants or wind farms, threatening security of electricity supply and driving higher prices in the long-run. Wind farms are an example of electricity generators that have very low SRMC - the wind is free - and so typically they receive a higher rate of infra-marginal rent than other electricity generators, which in turn is needed to pay for their much higher fixed costs. If a generator was dispatched more than it was scheduled to in the Market Schedule, for example to compensate for another (cheaper) generator not being brought online due to a network failure or "constraint", it is "constrained on". This means it receives its bid cost to compensate for the extra MW it has to produce, though it does not receive infra-marginal rent. Generators who were originally included in the Market Schedule, but not actually run for reasons outside of their control, for example due to a network fault, are said to be 
"constrained off". They receive the SMP less their bid, i.e. the infra-marginal rent they would have received in the market had they been run. Constraints costs also cover costs associated with "reserve". This is where, in order to ensure the continued security of the system, for example in the event of a generator tripping, some generators are instructed to run at lower levels than indicated in the Market Schedule. This means there is spare generation capacity available (reserve) which can be quickly brought online if needed. To maintain the demand-supply balance, this reserve means that some generators will be constrained down while others may be constrained on/up, again leading to the actual dispatch deviating from the Market Schedule (CER, 2011).

\section{Related work}

There is a small number of companies providing or working on a robust approach to forecasting both renewable power output and/or marginal prices for electricity. Alba Soluzioni ${ }^{2}$ are an independent consultancy providing information, training and bespoke consultancy services in the European gas and power markets. Their primary publication to date is considered a reference on Italian gas \& power markets. They currently provide a short-term marginal price forecast service. MKOnline ${ }^{3}$ provides online market intelligence services to provide clients with timely and high resolution forecasts of fundamentals and prices for the short, mid and long term horizon. It also offers a complementary weather service.

Meteologica ${ }^{4}$ supply forecasts of business variables related to weather through the provision of integrated forecasting solutions, unique to each client. Meteologica specializes in wind and solar power forecasting services all around the world. Their forecasts are utilized by hundreds of plant owners, power traders and grid operators to optimize their business activities. From preliminary conversations as a potential supplier of renewable power output data, Meteologica is currently working on an SMP forecasting service. Meteogroup ${ }^{5}$ is a global private weather business with offices around the world. They aim to combine experience and global coverage with local expertise to offer our customers highly accurate and bespoke weather services. Meteogroup has recently launched a portal aimed at presenting meteorological information useful to energy traders.

(Osman et al., 2009) use an ANN-based load forecasting methods for 24-hour-ahead peak load forecasting by using forecasted temperature. They proposed a one hour-ahead load forecasting method using the most significant weather data. In the proposed forecasting method, weather data is first analyzed to determine the most correlated factors to load changes. The most correlated weather data is then used in training, validating and testing the neural network. Correlation analysis of weather data was used to determine the input parameters of the neural networks and they tested it on actual load data from the Egyptian Unified System.

(Sharma et al., 2012) outline a neural network approach for forecasting short-term electricity prices using a back propagation algorithm. The results obtained from their neural network show that the neural network based approach is more accurate. (Buhari and Sani Adamu, 2012) present the development of an ANN based short-term load forecasting model for a substation in Kano, Nigeria. The recorded daily load profile with a lead time of 1-24 hours for the year 2005 was obtained from the utility company. The Levenberg-Marquardt optimization technique was used as a back propagation algorithm for the Multilayer Feed Forward ANN. The forecasted next day 24 hourly peak loads were obtained based on the stationary output of the ANN with a performance Mean Squared Error (MSE) of 5.84e $\mathrm{e}^{-6}$ and compared favorably with the actual Power utility data. The results showed that their technique is robust in forecasting future load demands for the daily operational planning of power system distribution sub-stations in Nigeria.

\section{Artificial Neural Networks \& Short-term Load Forecasting}

In machine learning and cognitive science, artificial neural networks (ANNs) are a family of models inspired by biological neural networks (the central nervous systems of animals, in particular the brain) and are used to estimate or approximate functions that can depend on a large number of inputs and are generally unknown. (McCulloch \& Pitts,

\footnotetext{
2 http://albasoluzioni.com

${ }^{3}$ http://www.mkonline.com

${ }^{4}$ http://www.meteologica.com/meteologica/content/effect-wind-power-generation-power-prices

${ }^{5}$ http://www.meteogroup.com
} 
1943). Artificial neural networks are generally presented as systems of interconnected "neurons" which exchange messages between each other ${ }^{6}$. The connections have numeric weights that can be tuned based on experience, making neural nets adaptive to inputs and capable of learning. For example, a neural network for handwriting recognition is defined by a set of input neurons which may be activated by the pixels of an input image. After being weighted and transformed by a function (determined by the network's designer), the activations of these neurons are then passed on to other neurons (Rosenblatt, 1958). This process is repeated until finally, an output neuron is activated. This determines which character was read. Like other machine learning methods - systems that learn from data - neural networks have been used to solve a wide variety of tasks that are hard to solve using ordinary rule-based programming, including computer vision and speech recognition (Forouzanfar, 2010).

For short-term load forecasting, the Back Propagation Network (BP) network is the most widely used one. Due to its ability to approximate any continuous nonlinear function, the BP network has extraordinary mapping (forecasting) abilities. The BP network is a kind of multilayer feed forward network, and the transfer function within the network is usually a nonlinear function such as the Sigmoid function. The typical BP network structure for short-term load forecasting is a three-layer network, with the nonlinear Sigmoid function as the transfer function (Schmidhuber, 2015). Fully connected BP networks need more training time and are not adaptive enough to temperature changes therefore some have moved to using non-fully connected BP models (Graves et al., 2009). Although a fully connected ANN is able to capture the load characteristics, a non-fully connected ANN is more adaptive to respond to temperature changes. Results also show that the forecasting accuracy is significantly improved for abrupt temperature changing days. There is also merit in combining several sub-ANNs together to give better forecasting results such as using recurrent high order neural networks (RHONN) (Graves \& Schmidhuber, 2009). Due to its dynamic nature, the RHONN forecasting model is able to adapt quickly to changing conditions such as important load variations or changes of the daily load pattern (Graves et al., 2009). A back propagation network is a type of array which can realize nonlinear mapping from the inputs to the outputs. Therefore, the selection of input variables of a load forecasting network is very important. In general, there are two selection methods. One is based on experience and the other is based on statistical analysis such as the ARIMA and correlation analysis.

For instance, we can denote the load at hour $\mathrm{k}$ as $1(\mathrm{k})$ so a typical selection of inputs based on operation experience will be $1(\mathrm{k}-1), 1(\mathrm{k}-24), \mathrm{t}(\mathrm{k}-1)$, where $\mathrm{t}(\mathrm{k})$ is the temperature corresponding to the load $\mathrm{l}(\mathrm{k})$. Unlike those methods which are based on experience, we can apply auto-correlation analysis on the historical load data to determine the input variables. Auto-correlation analysis should show that correlation of peaks occurs at the multiples of 24 hour lags. This indicates that the loads at the same hours have very strong correlation with each other. Therefore, they can be chosen as input variables. In addition to using conventional information such as historical loads and temperature as input variables, wind-speed, sky-cover can also be used. Potential input variables could be historical loads, historical and future temperatures, hour of day index, day of week index, wind-speed, sky-cover, rainfall and wet or dry days. There are no hard fast rules to be followed to determine input variables. This largely depends on engineering judgment and experience. Previous research (Rui \& El-Keib, 1995) has found that for a normal climate area, historical loads, historical \& future temperatures, hour of day and day of week index are sufficient to give acceptable forecasting results. However, for an extreme weather-conditioned area the other input variables classes were recommended, because of the highly nonlinear relationship between the loads and the weather conditions.

\section{A Short Term Electricity Market Forecasting Model}

Artificial Neural Networks (ANNs) can only perform what they were trained to do. Therefore to achieve short term load forecasting, the selection of the training data is a crucial one. The criteria for selecting the training set is that the characteristics of all the training pairs in the training set must be similar to those of the day to be forecasted. Choosing as many training pairs as possible is not the correct approach for a number of reasons. On reason is load periodicity. For instance, each day of the week has different patterns. Therefore, using Sundays' load data to train the network which is to be used to forecast Mondays' loads would lead to wrong results. Also, as loads possess different trends in different periods, recent data is more useful than old data. Therefore, a very large training set which includes old data is less useful to track the most recent trends.

\footnotetext{
${ }^{6}$ https://en.wikipedia.org/wiki/Artificial_neural_network
} 
Therefore to obtain good forecasting results, day type information must be taken into account. We can achieve this by constructing different ANNs for each day type, and feeding each ANN the corresponding day type training sets (Papalexopoulos, 1993; Lee, 1992). Another way is to use only one ANN but contain the day type information in the input variables (Srinivasan, 1994). The two methods have their advantages and disadvantages. The former uses a number of relatively small size networks, while the latter has only one network of a relatively large size. The day type classification is system dependent e.g. the load on Monday may be similar to that on Tuesdays but not always. Therefore one option is to classify historical loads into classes such as Monday, Tuesday-Thursday, Friday, Saturday, and Sunday/Public holiday. The Back Propagation algorithm is widely used in short-term load forecasting and has some good features such as, its ability to easily accommodate weather variables, and its implicit expressions relating inputs and outputs but it is also a time consuming training process and its convergence to local minima (Lee, 1993; Ciresan et al., 2012). The determination of the optimal number of hidden neurons is a crucial issue. If it is too small, the network cannot possess sufficient information, and therefore yields inaccurate forecasting results. On the other hand, if it is too large, the training process will be very long (Balabin et al., 2009).

Other important factors are to determine how big the prediction window should be. For instance, it could possibly be cold in one month so is this valid 12 months later. The forecast horizon is day $+1-$ and for remainder of day. This is for the next available market. The model may also provide predictions for 48/72 hours. This will lead of course to dimensioned results but we associate a corresponding error value. Not all electricity markets follow the same slots so in practice we aim to weather forecast, model network topology and more. Some of the main factors for forecasting are demand forecast, estimated power production capability and available interconnection capacity. Outliers include weather events, solar eclipses so we must also be careful not to factor into our model. The initial stage involves determining the input variables from the demand, power production and price prediction data we download from $\mathrm{SEMO}^{7}$. See Table 1 .

\begin{tabular}{|l|l|l|}
\hline Variables name & The unit of measurement & Example \\
\hline Trade date & Day of month & 1 Feb 2016 \\
\hline Delivery date & Half Hour & 1 Feb 2016 06:00 \\
\hline Jurisdiction & & ROI/NI \\
\hline Forecast MW & Megawatts & 2551.98 \\
\hline Solarpower & Megawatts & 0 \\
\hline Solarpower Utilization & $\%$ & 0 \\
\hline Windpower & Megawatts & 2022 \\
\hline Windpower Utilization & $\%$ & 81 \\
\hline SMP & Euro & 18.9 \\
\hline Shadow Price & Euro & 18.809999 \\
\hline
\end{tabular}

Table 1: Key data fields

We plot a subset of data. Figure 4 shows Solar power production in Northern Ireland. The value of horizontal axis is time domain from $1^{\text {st }}$ Feb 2016 to $9^{\text {th }}$ Feb 2016. The Red line indicates the solar power production (MW) in Northern Ireland and the blue line indicates the solar power utilization rate (\%) in Northern Ireland.

\footnotetext{
${ }^{7}$ http://www.sem-o.com
} 


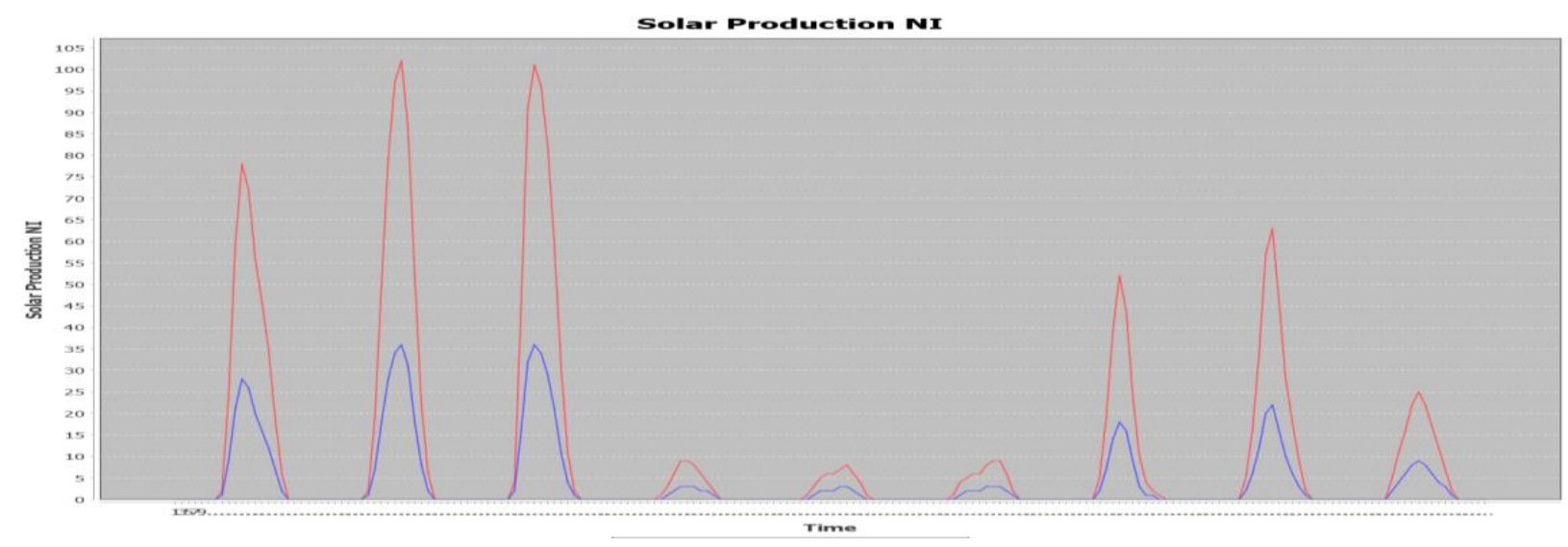

Figure 4: Solar power production in Northern Ireland

In Figure 5, the Red line indicates the wind power production (MW) in Northern Ireland and the blue line indicates the wind power utilization rate $(\%)$ in Northern Ireland.

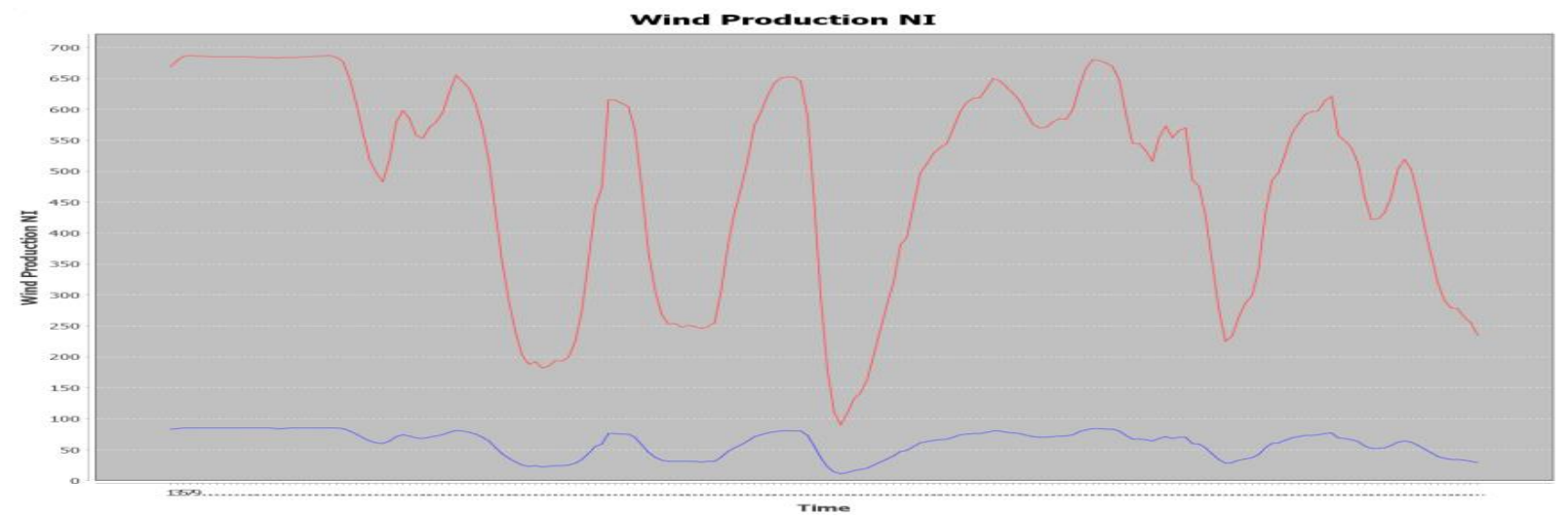

Figure 5: Wind Production power in Northern Ireland

In Figure 6, the Red line indicates the wind power production (MW) in the Republic of Ireland and the blue line indicates the wind power utilization rate (\%) in the Republic of Ireland. There is no solar power production in the Republic of Ireland.

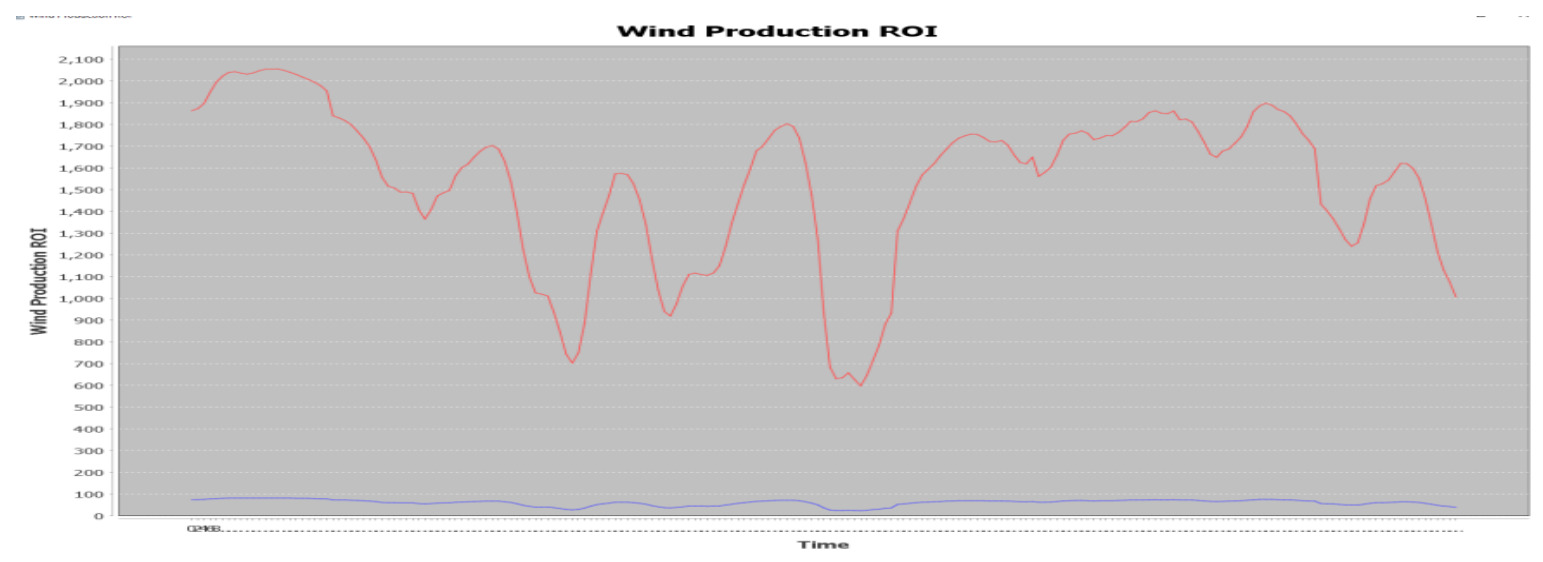

Figure 6: Wind Production power in Republic of Ireland 
Figure 7 shows the demand prediction (Megawatts) of the Republic of Ireland and Northern Ireland. The Red line indicates the demand (MW) in Republic of Ireland and the blue line indicates the demand (MW) in Northern Ireland.

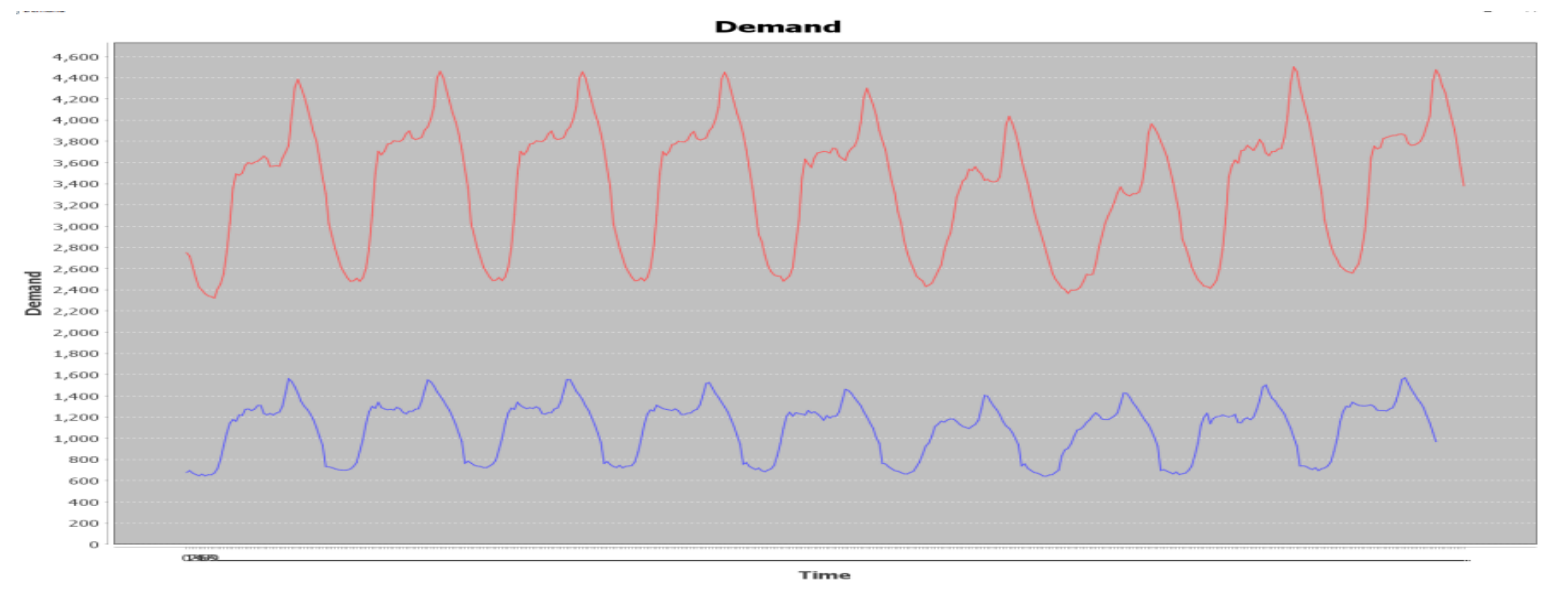

Figure 7: Demand prediction in Republic of Ireland

Figure 8 shows the SMP for North and South. The Red line indicates the SMP (Euro) in the Republic of Ireland and the blue line indicates the shadow price (Euro) in the Republic of Ireland.

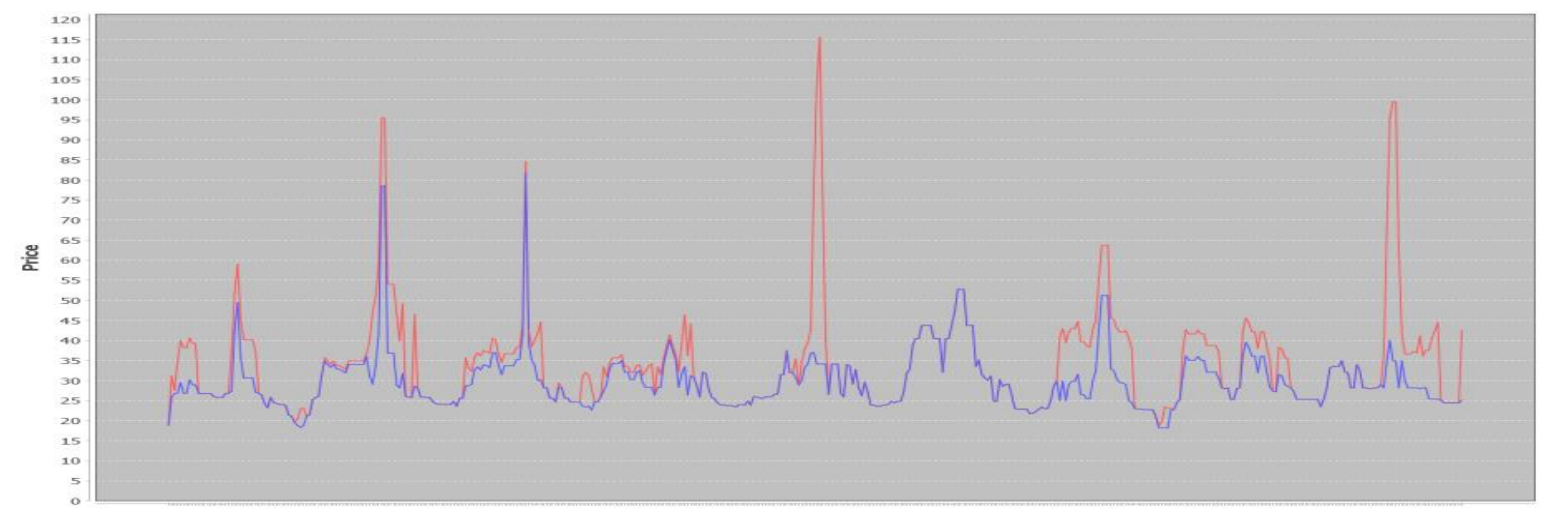

Figure 8: SMP in Northern Ireland and Republic of Ireland

Time series prediction is one of the most important prediction that collect past observations of a variable and analyze it to obtain the underlying relationships between historical observations but time series has properties such as nonlinearity, chaotic, non-stationary and cyclic which cause problems. An adaptive neural network based fuzzy inference system (ANFIS) is where the learning processes are performed by interleaving the optimization of the antecedent and conclusion parts parameters. The ANFIS model we are using is a Takagi-type Neuro-fuzzy Network which combines neural networks and fuzzy systems. Fuzzy reasoning and network calculation will be available simultaneously.

Before we employ the ANFIS method to forecast the daily electricity SMP data, the raw data need to be preprocessed to get the proper input and we need to determine the data input variables. One input data sample input consists of Production Forecasting (D-2), Load Forecasting (D-2) and Previous Prices Window (D-9... D-2). The data of production forecasting and load forecasting can be obtained from the Ex-Ante lag-2 file. The data of previous prices window can be obtained from the Ex-Ante files of lag-2, lag-3, .., lag-9. Production forecasting includes $9 * 2 * 48$ variables, Load Forecasting includes $4 * 2 * 48$ variables and Previous Prices Window includes $7 * 2 * 48$ variables. Output (D) includes 48 variables to compare with control data. 


\begin{tabular}{|c|c|c|c|c|c|c|}
\hline & $\begin{array}{l}\text { Production } \\
\text { Forecasting }\end{array}$ & $\begin{array}{l}\text { Load } \\
\text { Forecasting }\end{array}$ & Previous Prices Window & Output & $\begin{array}{l}\text { Control } \\
\text { (Output) }\end{array}$ & Data \\
\hline Data Sample 1 & $\begin{array}{l}\text { D-2 (9-day } \\
\text { Forecasting) }\end{array}$ & $\begin{array}{l}\text { D-2 (4-day } \\
\text { Forecasting) }\end{array}$ & $\begin{array}{l}\mathrm{EA}(\mathrm{D}-9), \quad \mathrm{EA}(\mathrm{D}-8), \quad \ldots \\
\mathrm{EA}(\mathrm{D}-2)\end{array}$ & $\mathrm{D}$ & $\begin{array}{l}\mathrm{EA}(\mathrm{D})= \\
\mathrm{H} 2, \ldots)\end{array}$ & (H1, \\
\hline Data Sample 2 & D-3 & D-3 & $\begin{array}{l}\mathrm{EA}(\mathrm{D}-10), \quad \mathrm{EA}(\mathrm{D}-9), \ldots \\
\mathrm{EA}(\mathrm{D}-3)\end{array}$ & D-1 & $\mathrm{EA}(\mathrm{D}-1)$ & \\
\hline ... & $\ldots$ & $\ldots$ & $\ldots$ & $\ldots$ & $\ldots$ & \\
\hline
\end{tabular}

Table 2: Four day rolling load forecast sample

Currently, we are experimenting with other algorithm to determine the parameters of the ANFIS model (Grid Partitioning, subtractive clustering and FCM clustering), training method (SOM algorithm, Levenberg-Marquardt algorithm, Bayesian Regularization and Scaled Conjugate Gradient), AR model, state space model and ARIMAX model, Neural Network and Fuzzy Inference System.

\section{Conclusion}

Short-term load forecast is an essential part of electric power system planning and operation. Forecasted values of system load affect the decisions made for unit commitment and security assessment, which have a direct impact on operational costs and system security. Conventional regression methods are used by most power companies for load forecasting. However, due to the nonlinear relationship between load and factors affecting it, conventional methods are not sufficient enough to provide accurate load forecast or to consider the seasonal variations of load. ANN-based load forecasting methods can deal with 24-hour-ahead load forecasting by using forecasted weather input variables, which can lead to high forecasting errors in case of rapid weather changes.

This paper presents our early stage attempts to create a novel neural network based approach for short-term load forecasting that uses the correlated weather data for training, validating and testing of a neural network. Correlation analysis of weather data determines the input parameters of the neural networks. The suitability of the proposed approach is illustrated through an application to the actual load data of the Irish Electricity Market. We may also make used of Microsoft Azure Machine Learning and IBM APIs cognos for experimenting with different ML algorithms. Azure ML could be useful as quick and easy to export to web services and bring online with minimum fuss. It has a wide range of plug-ins. A problem however is that it is a black box and but still potentially useful for early stage quick tests.

\section{References}

Balabin, R., Lomakina, E. (2009). Neural network approach to quantum-chemistry data: Accurate prediction of density functional theory energies. J. Chem. Phys. Vol. 131, No. 7, pp: 74-104. doi:10.1063/1.3206326. PMID 19708729.

Baliyan, A., Gaurav, K., Kumar Mishra, A. (2015) A Review of Short Term Load Forecasting using Artificial Neural Network Models, Procedia Computer Science, Volume 48, 2015, Pages 121-125, ISSN 1877-0509, http://dx.doi.org/10.1016/j.procs.2015.04.160.

Buhari, M., Sani Adamu, S. (2012) Short-Term Load Forecasting Using ArtificialvNeural Network Proceedings of the International Multi-conference of Engineers and Computer Scientists, Vol. I., IMECS 2012, March 14-16, Hong Kong

CER (2011) CER Factsheet on the Single Electricity Market, Commission for Energy Regulation, April 2011 http://www.cer.ie/docs/000262/cer11075.pdf

Ciresan, D., Meier, U., Schmidhuber, J. (2012) Multi-column Deep Neural Networks for Image Classification. IEEE Conf. on Computer Vision and Pattern Recognition CVPR 2012. 
Forouzanfar, M., Dajani, H., Groza, V., Bolic, M., and Rajan, S. (2010). Comparison of Feed-Forward Neural Network Training Algorithms for Oscillometric Blood Pressure Estimation, 4th Int. Workshop Soft Computing Applications. Arad, Romania: IEEE.

Graves, A., Schmidhuber, J. (2009) Offline Handwriting Recognition with Multidimensional Recurrent Neural Networks, in Bengio, Yoshua; Schuurmans, Dale; Lafferty, John; Williams, Chris K. I.; and Culotta, Aron (eds.), Advances in Neural Information Processing Systems 22 (NIPS'22), 7-10 December 2009, Vancouver, BC, Neural Information Processing Systems (NIPS) Foundation, 2009, pp. 545-552.

Graves, A., Liwicki, M., Fernandez, S., Bertolami, R., Bunke, H., Schmidhuber. J. (2009) A Novel Connectionist System for Improved Unconstrained Handwriting Recognition. IEEE Transactions on Pattern Analysis and Machine Intelligence, vol. 31, no. 5, 2009.

Lee, K. (1992) Short-Term Load Forecasting Using an Artificial neural Network, IEEE Trans. On Power Systems, Vol. 7, No. 1, pp. 124-131, Feb.1992.

Lee, Y. (1993) An Analysis of Premature Saturation index Back Propagation Learning, Neural Networks, Vol. 6, pp. 719-728, 1993.

McCulloch, Warren; Walter Pitts (1943). A Logical Calculus of Ideas Immanent in Nervous Activity. Bulletin of Mathematical Biophysics, Vol. 5, No. 4, pp: 115-133, doi:10.1007/BF02478259.

Mohammed, O. (1994) Practical Experiences with an Adaptive Neural Network short-term load forecasting system, IEEE/PES 1994 Winter Meeting, Paper \# 94 210-5 PWRS.

Osman, Z., Awad, M., and Mahmoud, T. (2009) Neural network based approach for short-term load forecasting, Power Systems Conference and Exposition, 2009. PSCE '09. IEEE/PES, Seattle, WA, 2009, pp. 1-8.

doi: 10.1109/PSCE.2009.4840035

Park, D. (1991) Electric load forecasting using an artificial neural network, IEEE Trans. on Power Systems, Vol. 6, No. 2, pp. 412-449, May 1991.

Papalexopoulos, A. (1993) Application of neural network technology to short-term system load forecasting, pp. 796-800, Proceedings, IEEE Second International Forum on the Applications of Neural Networks to Power Systems, April, 1993,

Yokohoma, Japan.

Rosenblatt, F. (1958). The Perceptron: A Probabilistic Model for Information Storage And Organization In The Brain. Psychological Review, Vol: 65, No. 6, pp: 386-408. doi:10.1037/h0042519.PMID 13602029.

Rui, Y. \& El-Keib, A. (1995) A review of ANN-based Short-term load forecasting models, Proc. Of $27^{\text {th }}$ South Eastern Symposium on System Theory, Starkville, MS, 12-14 March 1995, pp: 78-82

Schmidhuber, J, (2015). Deep learning in neural networks: An overview. Neural Networks, Vol. 61, pp: 85117. arXiv:1404.7828. doi:10.1016/j.neunet.2014.09.003.

Sharma, L., Chakrawarti, M., Dutta, A., Adhikari, N. (2012) Neural Network Based Approach for Short-term Load Forecasting, International Journal of Science, Environment and Technology, Vol. 1, No 5, 2012, 416 - 424

Srinivasan, D. (1994) A neural network short-term load forecaster, Electric Power Research, pp. 227-234, 28 (1994).

Werbos, P.J. (1975). Beyond Regression: New Tools for Prediction and Analysis in the Behavioral Sciences.

Wu, J., Chen, E. (2009). Wang, H., Shen, Y., Huang, T., Zeng, Z., ed. A Novel Nonparametric Regression Ensemble for Rainfall Forecasting Using Particle Swarm Optimization Technique Coupled with Artificial Neural Network. 6th International Symposium on Neural Networks, ISNN 2009. Springer. doi:10.1007/978-3-642-01513-7-6. 